\title{
Implantação do gerenciamento de rotina e 5s numa distribuidora
}

Implementation of routine and 5s management in a distributor

Raul de Sá Cavalcanti Albuquerque 1,2 (b) orcid.org/0000-0001-6898-3531

Luciana Bazante de Oliveira 2,3 orcid.org/0000-0001-9115-896X

${ }^{1}$ Escola Politécnica de Pernambuco, Universidade de Pernambuco, Recife, Brasil,

2 Pós-graduação em Gestão da Qualidade e Produtividade, Escola Politécnica de Pernambuco, Pernambuco, Brasil,

3 Escola Politécnica de Pernambuco, Recife, Pernambuco, Brasil.

E-mail do autor principal: Raul de Sá Cavalcanti Albuquerque raulmarrone@msn.com

\section{Resumo}

A globalização da economia vem forçando as empresas a buscarem por maior competitividade e, assim também, a eficiência nos processos/serviços. Se não continuarem os seus esforços por melhorias e aprimoramentos, poderão correr o risco de perder a competitividade atingida e terem seu espaço ocupado por concorrentes. A forma mais adequada de obter tal competitividade é a busca por qualidade, através da adoção de técnicas, metodologias e ferramentas gerenciais, onde todas as ações sejam previamente planejadas e discutidas. Neste contexto se enquadram o gerenciamento da rotina e os sistemas de gestão da qualidade que têm como base o $5 \mathrm{~S}$. Este trabalho visa apresentar aplicação do GR e $5 \mathrm{~S}$ para proporcionar a redução de desperdícios dos produtos devido a exceder o prazo de validade na área de estocagem

Palavras-Chave: Gerenciamento da Rotina; 5S; Gestão; Qualidade.

\section{Abstract}

The globalization of the economy has been forcing companies to seek for greater competitiveness and, thus, efficiency in processes / services. If they do not continue their efforts for improvements and improvements, they may run the risk of losing their competitiveness and having their space occupied by competitors. The most appropriate way to achieve such competitiveness is the search for quality, through the adoption of techniques, methodologies and management tools, where all actions are planned and discussed previously. In this context, the routine management and the quality management systems based on $5 \mathrm{~S}$ are included. This work aims to present application of the $G R$ and $5 S$ to provide the reduction of waste products due to exceeding the shelf life in the storage area.

Key-words: Routine Management; 5s; Management; Quality 


\section{Introdução}

A implantação de sistemas de gestão de qualidade não se originou apenas por modismo ou tampouco nasceu de projetos acadêmicos. Segundo afirmação de Lopes; Pereira; Vieira [1]:

"Nas últimas décadas, a abertura do mercado nacional à concorrência estrangeira em vários setores e o crescimento da economia brasileira contribuíram para a entrada de novas empresas no mercado. Como resultado, satisfazer os clientes se tornou um dos aspectos chave na estratégia mercadológica de várias empresas".

Hoje vivemos num mundo onde as mudanças são muito rápidas, as empresas precisam cada vez mais desenvolver sistemas suficientemente fortes e ágeis para criar condições internas de tal forma a garantir a sobrevivência das mesmas. Para isto devemos estar atentos aos fatores como: qualidade, produtividade, competitividade e sobrevivência.

Com relação ainda à crescente competição mundial, composta por organizações e países cada vez mais competitivos, a necessidade de padronização de produtos para maior sucesso na comercialização entre os povos, fez com que o homem, ora por tentativa e erro, ora pela adoção de modelos científicos, aprimorasse produtos e serviços numa velocidade muito acentuada nos últimos 50 anos. Tal situação propiciou um alto grau de desempenho às organizações que optaram pelo caminho da qualidade [2].

O modo de vida dos consumidores e a eficiência das empresas em seus ramos de negócio passaram a depender do desempenho confiável e consistente de produtos e serviços, sem haver tolerância para a perda de tempo e custos de falhas. A qualidade, portanto, torna-se estratégia básica para a atual competitividade.

Em relação aos programas de gestão da qualidade, mais especificamente no setor de serviços, o número de implantações é bem menos expressivo que na área da indústria. No entanto, a simples existência e implantação de um sistema oficial de gestão da qualidade definido não é suficiente para garantir o sucesso de uma organização. O processo real, praticado, deve estar alinhado com o processo oficial documentado, que, por sua vez, deve ser adequado aos objetivos e características da organização. Caso contrário, o processo oficial não é espelhado pelo real, e torna-se apenas mais um entrave burocrático.

Essa melhoria do processo real deve ser realizada adotando-se um programa de melhoria da organização em processos e pessoas, que contemple as necessidades da organização. Para fazê-lo de forma sistemática, verificável, controlável e contínua, é preciso que esse programa também seja conduzido de acordo com um processo bem definido e documentado. Segundo Mello ET AL [2], "se essa evolução for reconhecida a tempo por um gerente bem informado e hábil, ele poderá entrar no circuito, no ponto onde existe a maturidade, e propor o redesenho do processo, devolvendo-Ihe a eficácia".

Percebendo essa problemática e analisando a estocagem, uma distribuidora de produto químicos situada em Pernambuco, decidiu remodelar sua estrutura. Foi, então, implantado um novo sistema de serviços, baseado nas ferramentas e metodologias da qualidade ( $5 \mathrm{~S}$ e gerenciamento da rotina, mais especificamente) identificando os desperdícios e suas causas. O cenário encontrado antes da introdução desse sistema, havia uma perda de estoque por validade dos produtos de quase $80 \%$.

\section{Objetivos}

\subsection{Objetivo geral}

Aumentar a probabilidade de ampliar a satisfação do cliente e outras partes interessadas, demonstrando a necessidade de aplicação da gestão e suas ferramentas para melhorar os serviços prestados e eliminar a perda de produtos no estoque devido a exceder o seu tempo de validade, assim possibilitando maior estocagem dos produtos rotativos.

\subsection{Objetivos específicos}

- Proporcionar às pessoas que trabalham nos diversos departamentos o desenvolvimento de seus valores humanos e dos conhecimentos funcionais para a qualidade e produtividade;

- Apresentar os conceitos de ferramentas e metodologias escolhidas para o trabalho;

- Descrever o processo de implementação das ferramentas na organização; 
- Redução de custos com perdas;

- Apresentar resultados e contribuições obtidas na organização.

\section{Metodologia}

A metodologia adotada foi um trabalho de intervenção em uma empresa de serviços de distribuição de produtos químicos, localizada na Região Metropolitana do Recife. Foi realizada a observação dos fatos, levantamento do número de produtos vencidos e a aplicação efetiva de ferramentas da qualidade e $5 S$ para alcançar a redução das perdas por validade.

\section{Revisão de literatura}

\subsection{Gestão da Qualidade Total}

A Gestão da Qualidade Total é um programa abrangente que visa aplicar e garantir a qualidade em todos os processos que culminam na entrega de um produto, seguindo especificações e adequações de uso. Neste sentido, Gomes e Cervi (2013) [3] discorrem que a gestão da qualidade total possui dentre seus objetivos, a criação de condições internas que garantam sobrevivência em longo prazo, através da constante e integradora melhoria dos processos de todos os departamentos da empresa, voltada a planejar, produzir e vender um produto que satisfaça e supere as necessidades de seus clientes. Para atingir os objetivos do programa, algumas ferramentas são de extrema importância, sendo conhecidas como ferramentas gerenciais da qualidade, tais como as apresentadas a seguir [4]:

- $\quad$ Brainstorming (tempestade de ideias);

- $\quad$ Folha de verificação;

- Diagrama de Pareto;

- Diagrama de Ishikawa.

\subsection{Brainstorming}

Também chamada de tempestades de ideias, essa ferramenta envolve pessoas que farão contribuirão com suas ideias sobre as causas de um problema e/ou sobre soluções relacionadas a ele. Segundo Rozenfeld (2006) [5], trata-se de uma metodologia para a busca de soluções criativas.

112

\subsection{Folha de verificação}

O "Check-List" ou Folha de Verificação é uma ferramenta usada para padronizar e verificar resultados de um trabalho, ou para verificar e coletar dados onde mostra um perfil dos acontecimentos, respondendo qual a frequência observada de um determinado problema [6].

A coleta dos dados é o início para qualquer estudo de problemas, e, portanto, deve ser bem planejada. De modo geral pode-se distinguir 4 tipos de listas de verificação:

- Lista de verificação da existência de determinadas condições. Geralmente a resposta final que interessa é do tipo SIM/NÃO;

- Lista de verificação de contagem de quantidades. Neste tipo de lista, além de se verificar a existência ou não das condições exigidas, interessa saber as quantidades ou frequências com que aparecem. Exemplo: lista de verificação de defeitos de acabamento da peça;

- Lista de verificação de classificação de medidas. Neste tipo de lista, se verifica o modo de distribuição de características mensuráveis. Exemplo: distribuição das medidas dos diâmetros de uma determinada peça;

- Lista de verificação de localização de defeitos. Esta lista serve para se estudar a localização de defeitos ou determinadas características em corpos ou objetos definidos, com a finalidade de se perceber algum padrão de ocorrência. Exemplo: Lista de verificação de defeitos de acabamento na parte externa da peça.

\subsection{Diagrama de Ishikawa}

O diagrama de Ishikawa é uma técnica largamente utilizada, que mostra a relação entre um efeito (problema) e as possíveis causas que podem estar contribuindo para que ele ocorra. Com a aparência de uma espinha de peixe, essa ferramenta foi aplicada, pela primeira vez em 1953 no Japão por Kaoru Ishikawa [7].

Ela pode ser utilizada para organizar as ideias obtidas no brainstorming (ferramenta usada para coleta de ideias), facilitando a verificação e identificação das possíveis causas de um problema http:/ / dx.doi.org/10.25286/repa.v4i1.952 
e, também, identificação de suas soluções. O diagrama é dividido em seis causas possíveis: máquina, mão de obra, material, método, meio ambiente e medida. Para organizar este diagrama, primeiro é identificado o efeito do problema a ser estudado, que é registrado no desenho que representa a cabeça do peixe e, em seguida, são registradas, nas espinhas, as causas que podem provocar o problema como mostra a Figura 1.

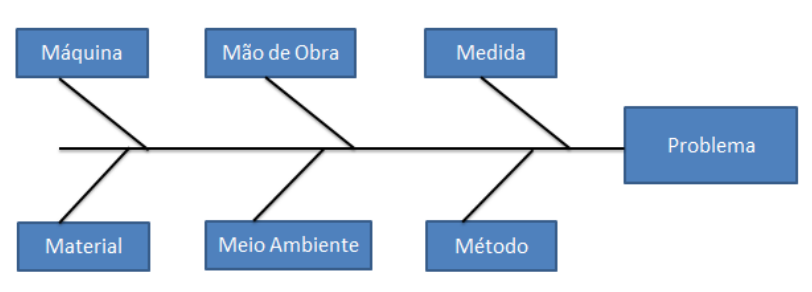

Figura 1: Diagrama de Ishikawa

Fonte: Autor

\subsection{Gerenciamento da Rotina}

Moura [8] conceitua Gerenciamento da Rotina como a "ação de coordenar e executar as atividades do dia-a-dia em nível operacional, praticando o ciclo PDCA (Planejar, Desenvolver, Checar e Agir) e executando as atividades de acordo com as políticas e diretrizes da empresa".

Para Campos [9], é muito difícil gerenciar bem se as funções operacionais não funcionam bem. Diz ele que em geral numa organização, a grande maioria das pessoas consome a maior parte do seu tempo trabalhando nestas funções operacionais e que para se arrumar a casa é necessário que as pessoas que atuam nessas funções sejam as melhores do mundo naquilo que fazem.

Como já foi mencionado anteriormente, gerenciar é resolver problemas e problemas são resultados indesejados. Com a padronização e o cumprimento desses padrões por todos aqueles que integram o processo, eliminam-se as anomalias e a ausência delas faz parte da arrumação da casa.

Campos [9] também salienta a importância do gerenciamento da rotina do trabalho do dia-a-dia, pois este está centrado: na perfeita definição de autoridade e da responsabilidade de cada pessoa; na padronização dos processos e do trabalho; na monitoração dos resultados destes processos e sua comparação com as metas; na ação corretiva no processo a partir dos desvios encontrados nos resultados quando comparados com as metas; num bom ambiente de trabalho e na máxima utilização do potencial mental das pessoas; e, na busca contínua da perfeição.

Para o autor o gerenciamento da rotina é a base da administração das organizações, devendo ser conduzido com o máximo cuidado, dedicação, prioridade, autonomia e responsabilidade, tendo em vista que à medida que o gerenciamento da rotina é implantado, os índices de defeitos caem e as especificações podem ser obedecidas integralmente. No entanto, alerta o autor, que somente isto não garante o sucesso na condução do processo em busca da qualidade, pois até se pode ter um processo perfeito, com um produto e/ou serviço sem defeitos, mas com especificações que não atendem às necessidades do cliente, ponto principal a ser atingido pelo TQC.

Para Santos, Lima e Abrantes [10] a rotina de uma organização é determinada pelos procedimentos operacionais que constituem um processo. Logo, dizem os 14 autores, Gerenciamento da Rotina Diária - GDR é a definição dos parâmetros a serem utilizados na condução de tais procedimentos, de maneira satisfatória à obtenção de qualidade no serviço.

O GDR faz parte do gerenciamento pelas diretrizes e é um desdobramento do modelo de qualidade, que visa à prática do Controle da Qualidade Total por um processo de garantia da qualidade, baseado no gerenciamento participativo. A utilização do Gerenciamento da Rotina como ferramenta da gestão pela qualidade, promove uma organização dos processos, bem como estabelece a tomada de decisão baseada nos fatos identificados por meio de um controle de processos, capacitando a gerência para uma visão de futuro das metas a serem atingidas (SANTOS, LIMA e ABRANTES, [10]).

O Instituto de Desenvolvimento Gerencial INDG, gerencia a rotina do trabalho do dia-a-dia é uma metodologia de trabalho utilizada para qualificar os componentes da organização a atingir suas metas 
e manter os melhores resultados de desempenho nos processos pelos quais são responsáveis, no que tange aos aspectos de qualidade, custo, entrega, segurança e meio ambiente.

O INDG recomenda a aplicação desta metodologia em organizações de qualquer natureza, sejam públicas ou privadas, que apresentem resultados insatisfatórios em função de uma baixa eficiência no desempenho de seus processos, tanto administrativos como produtivos. Para tanto, é necessária a realização de diagnóstico que permita avaliar e analisar o sistema de gerenciamento da rotina da empresa, identificando as deficiências sistêmicas de gestão que comprometem a melhoria e a estabilidade dos seus resultados.

\section{$4.65 S$}

O $5 S$ busca uma melhor qualidade de vida, prevenção de acidentes e melhoria da produtividade na organização [11]. É denominada 5S por conta de 5 palavras japonesas que começam com a letra "S". Traduzindo para o português ficaram conhecidas como os 5 sensos [12]. São eles:

$$
\begin{aligned}
& \text { - } \quad \text { Seiri - Senso de utilização; } \\
& \text { - } \quad \text { Seiton - Senso de ordenação; } \\
& \text { - } \quad \text { Seisou - Senso de limpeza; } \\
& \text { - } \quad \text { Shitsuke - Senso de saúde; } \\
& \hline
\end{aligned}
$$

O $5 S$ visa buscar a padronização das operações realizadas possibilitando a melhoria visual, física e, sem dúvida, da qualidade do serviço, a identificação desses desperdícios, aumentando a satisfação dos funcionários e consequentemente a segurança no ambiente a que são expostos.

\section{Resultados}

\subsection{Implantação das ferramentas da qualidade}

Em fevereiro de 2016, foi relatado pelo chefe do depósito que a empresa estudada tinha uma grande quantidade de produtos vencidos estocados e que esses produtos estavam ocupando espaço nos galpões. A partir daí, foi sugerida a utilização das ferramentas da qualidade para identificar e solucionar os problemas de tanto produto vencido.

Foi realizado um brainstorming, para que os colaboradores participassem com as suas ideias, sendo os envolvidos na expedição e armazenagem, juntamente com o setor do controle da qualidade. Com as ideias propostas, foi elaborado o diagrama de causa e efeito apresentado na Figura 3.

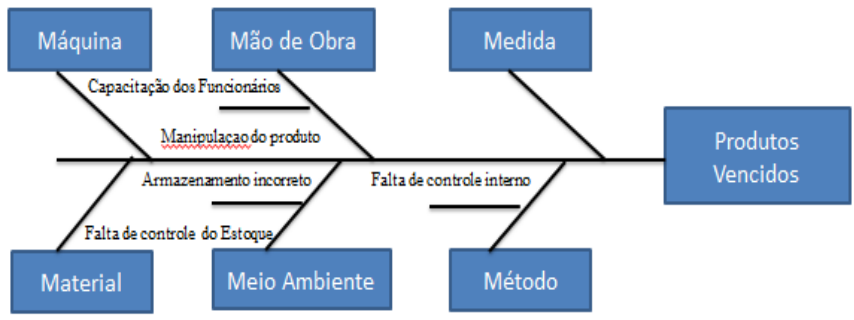

Figura 2: Diagrama de causa e efeito construído a partir do brainstorming

Fonte: Autor

Foi identificado que os possíveis problemas em relação aos produtos vencidos seriam provenientes de:

- Mão de obra, que estaria realizando procedimentos inadequados, fazendo as atividades sem atenção;

- Método, que estaria relacionado a falta de controle dos produtos que tem em estoque;

- Meio Ambiente, em relação ao meio externo ou interno, como temperatura, contaminação.

Quando o diagrama foi avaliado, foram observadas as causas e soluções do problema conforme abaixo listados:

Causa 1: A falta de controle interno dos produtos. Ação corretiva: 1 ○ Coletar amostras de todos os produtos assim que chegar, registrando o lote, o dia de fabricação, validade e o fornecedor (fabricante), ficando mais fácil saber qual produto está prestes a vencer ou chegaram com a data de validade próxima;

Foi implantado um procedimento para controle interno, que começou a ser realizado no mês de maio de 2016. Ao ser comparado ao ano anterior, após a implantação do controle, houve uma considerável redução de produtos vencidos.

http://dx.doi.org/10.25286/repa.v4i1.952 
Causa 2: Armazenamento incorreto. Ação corretiva: $1^{0}$ Implantar procedimento para frequentemente verificar se os produtos estão em seus respectivos Pallets, sem contato com o chão; $2^{\circ}$ Armazenar por tipo de classificados (riscos).

Causa 3. Capacitação dos funcionários. Ação corretiva: $1^{0}$ Fazer a cada mês, uma semana de "conhecimento" sobre manipulação dos produtos, segurança e limpeza.

Essa ação começou a ser realizada em agosto de 2016, sendo conduzida por cada representante do setor que passou pelo treinamento, onde houve a disseminação para os demais, tornando essa prática habitual.

\subsection{Identificação dos Produtos vencidos}

Foi elaborada uma lista de verificação em formato de planilha, para facilitar a coleta dos dados de interesse em relação aos produtos no estoque e poder tomar conhecimento sobre quais produtos estavam vencidos.

Após a estudo de campo, feito durante a primeira quinzena de dezembro de 2016, foram detectados $10.453 \mathrm{Kg}$ de produtos vencidos, conforme Figura 3:

\begin{tabular}{|c|c|c|c|c|}
\hline \multicolumn{2}{|c|}{ Check List/Produtos } & \multicolumn{3}{|c|}{ Periodo: Dezembro/2016 } \\
\hline Produto & Disp. em estoque & Data de Entrada & Validade & Revalidaçà \\
\hline ACESUUFAME-X IT 20100850 & 25,00 & 20/09/2011 & $04 / 10 / 2012$ & - \\
\hline ACDO ACtTCO Q. (ONU278s) & 10,00 & 17/07/2019 & $13 / 03 / 2016$ & . \\
\hline ALUMNATO OE 56001 [ONU23:12] & 700,00 & & & . \\
\hline ASEPTCOER & 225,00 & $09 / 06 / 2014$ & 24/08/2019 & . \\
\hline BEIZOATTO DE S6OIO GRAN EASTMAN & $=-50,00$ & - & - & . \\
\hline BCGBBONATO DE AMBMAa & 67,00 & 29/10/2012 & \multicolumn{2}{|c|}{ Acerto ose suso no estogue } \\
\hline CaRVZZO ATVADO RO (ONU1362] ] & 700,00 & 20/01/2014 & & - \\
\hline CORANTE Caramelo PO & 470,00 & $11 / 09 / 2010$ & 2009/2010 & - \\
\hline DEVAN 42 (ANTESPUMANTE BASE AQUOSA) & 80,00 & $17 / 08 / 2015$ & 17/10/2015 & $17 / 12 / 2015$ \\
\hline EP 2046 & 38,00 & \multicolumn{2}{|c|}{ AMOSTRA GRATIS } & . \\
\hline EP 2063 & 820,00 & $09 / 11 / 2011$ & $2012 / 12013$ & - \\
\hline FOSFATO DISSODICOO & 25,00 & $03 / 11 / 2010$ & & - \\
\hline FOSFATO TRICLLOCOO & 40,00 & $09 / 08 / 2010$ & 10/08/2012 & - \\
\hline HYPROX 500 & 1100,00 & $07 / 04 / 2014$ & $26 / 02 / 2015$ & . \\
\hline LACPRODAN SP 9225 IMP & 60,00 & $04 / 07 / 2014$ & $18 / 02 / 2016$ & - \\
\hline MALTODEXTRINA 20 & 250,00 & $18 / 01 / 2013$ & $08 / 01 / 2014$ & - \\
\hline potassa caustica & 725,00 & 14/01/2015 & $15 / 02 / 2016$ & . \\
\hline PRAESTOL 55515 & 75,00 & $27 / 05 / 2013$ & $26 / 10 / 2013$ & - \\
\hline PRAESTOL 853 & 25,00 & $13 / 08 / 2012$ & \multicolumn{2}{|c|}{ Acerto de saldo no estoque } \\
\hline SULCATO DE SODIO ALCALNO C224 & 560,00 & $24 / 09 / 2015$ & $23 / 03 / 2016$ & - \\
\hline SODA CAUSTICA ESC 7OS & 75,00 & $08 / 09 / 2010$ & \multicolumn{2}{|c|}{ Teste Tarcisio } \\
\hline XAROPE DE GUCOSE 25KG & 875,00 & $30 / 04 / 2013$ & $08 / 05 / 2014$ & - \\
\hline XAROPE DE GUCOSE 280KG & 2520,00 & 05/06/2013 & $03 / 05 / 2014$ & - \\
\hline TOTAL VENCDOS: & 10453,00 & & & \\
\hline
\end{tabular}

Figura 3: Check list de produtos vencidos Fonte: Autor

\subsection{Implantação do Gerenciamento de Rotina na Empresa}

A implementação do Gerenciamento de Rotina nem sempre ocorre facilmente, pois ele exige a aplicação de novas práticas e ferramentas e nem sempre os colaboradores estão abertos às mudanças e adaptações necessárias. Portanto, o líder é imprescindível nesse processo, pois ele será a pessoa que trabalhará em prol do envolvimento da equipe, apresentando as modificações necessárias e promovendo o relacionamento interpessoal, para que a mesma se comprometa com a organização e desenvolva um trabalho de excelência e alcance os melhores resultados para a empresa.

O primeiro passo foi padronizar os processos desempenhados na empresa, ou seja, o gestor uniu as demandas da organização e verificou as práticas das mesmas (recebimento, descarga, entrega e estoque) gerenciando os galpões e maquinas. A aplicação das ferramentas da qualidade mencionadas anteriormente foram um subtópico deste passo, pois deram subsídio à empresa para conhecer seus problemas e causas, além de rotinas importantes para serem padronizadas.

Cumprido o passo anterior, foi possível o aprofundamento nas tarefas que, por não serem executadas de forma adequada, causaram impacto negativo na empresa. Nesse ponto, foram definidos os objetivos para os processos identificados como críticos: ter a quantidade de produtos vencidos quase nula implantando $o 5 s$, onde a equipe envolvida foi capacitada para a execução do que foi proposto, monitorando os resultados obtidos $\mathrm{e}$ avaliando se as metas estão sendo atingidas.

\subsection{Implantação do $5 \mathrm{~S}$}

Como a empresa tem uma área de estocagem de produtos muito grande, tanto nacionais quanto importados, a busca sempre por redução de mercadorias vencidas passou a ser recorrente. Por isso, foram realizadas grandes transformações com a implantação do $5 S$.

No início, foram realizados treinamentos para todos os funcionários. A empresa priorizou aplicar seus investimentos nos 3 primeiros S's (senso de 
utilização, senso de ordenação e o senso de limpeza), atuando em áreas que tinham grande números de mercadorias nos galpões. Foi realizado um grande dia para descarte, limpeza e organização, quando todas as mercadorias com a data de validade conforme foram reorganizadas, o que proporcionou uma melhoria no fluxo e na logística.

Galpões praticamente inativos, antes utilizados para armazenar produtos vencidos e perigosos (pois os produtos perigosos e de riscos não podem ser descartados sem autorização do órgão competente e, ao serem descartados, precisam estar atrelados a uma empresa autorizada para descarte de produtos controlados e de riscos) foram esvaziados, restaurados e voltaram a fazer parte de uma área "viva", conforme ilustrado nas figuras 4 e 5 .

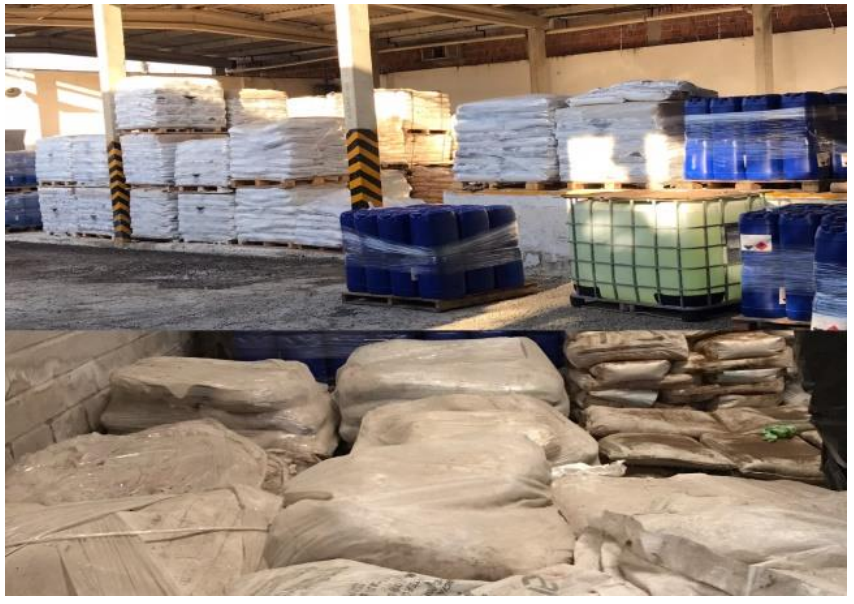

Figura 4: Foto antes - galpões cheios de produtos vencidos

Fonte: Autor

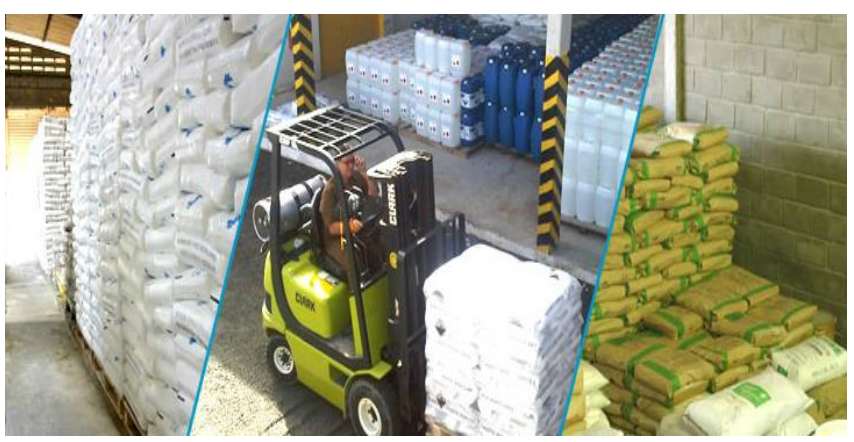

Figura 5: Foto depois - galpões esvaziados Fonte: Autor

Como é possível perceber na figura 4, havia uma grande quantidade de produtos sem uso, já vencidos, ocupando muito espaço e dispostos desordenadamente. Na figura 5 , é possível perceber que, após o descarte e reorganização, os depósitos foram utilizados para estocar produtos novos, de maneira mais ordenada, melhorando o fluxo no setor.

\subsection{Manutenção do uso das ferramentas da qualidade: ferramenta brainstorming como programa}

Para buscar a cultura da melhoria, foi iniciado um programa para tempestades de ideias com participação dos colaboradores da empresa para contribuir na redução dos desperdícios dentro da companhia. Esse programa teve como objetivo fazer com que todos os setores participassem do processo de transformação da organização, escutando e valorizando as ideias de seus integrantes.

As ideias podem partir de todos os colaboradores, visando conhecer causas dos problemas que muitos da área de estoque não visualizavam, como a questão do descarte de produtos vencidos ou área desorganizada. Nestes brainstormings, também surgiram ideias relacionadas à melhorias, mesmo que não diretamente ligadas ao problema inicial, tais como a otimização do descarrego das mercadorias, propostas para redução de gastos com energia, água, além de melhorar a qualidade de vida dos trabalhadores, como limpadores de olhos, bebedores mais próximos.

As causas dos problemas geradas no brainstorming foram organizadas no diagrama de Ishikawa, de forma a permitir a visualização das categorias onde se enquadravam.

\subsubsection{Gerenciamentos dos galpões e máquinas}

O gerenciamento dos galpões e das máquinas foi implantado a partir de sugestões na tempestade de ideias, para garantir que o adequado cumprimento das atividades, sendo realizadas de forma correta

http://dx.doi.org/10.25286/repa.v4i1.952 
em tempo hábil, para assim alcançar o objetivo traçado, conforme a estratégia da empresa.

Foi constatado que a empresa vinha utilizando métodos (descarrego, carregamento) que proporcionavam um processo rápido. Os indicadores funcionavam como um apontamento dos resultados, mas não eram viáveis para demonstrar os problemas que ocorriam ou suas causas. Sendo assim, os indicadores foram remodelados de forma simples, para buscar melhor entendimento sobre os resultados da empresa, e passaram a ser relatados a todos os setores, cada célula de trabalho passou a ter conhecimento sobre as variações, para que, a partir delas, fossem promovidas as aplicações das ferramentas de qualidade para análise e tomada de ações mais ágeis e eficazes. Os indicadores redefinidos foram:

- Segurança: Redução de acidentes;

- Qualidade: Redução de reclamações do serviço;

- $\quad$ Custo: quantidade de mercadorias vencidas

- $\quad$ Entrega: Atendimento nos prazos estipulados pelo cliente e a empresa.

Tais resultados passaram a ser atualizados nos quadros de gestão à vista pelo responsável do depósito, a cada duas horas, onde todos os envolvidos possam visualizar e conhecer os resultados em cada área do depósito.

\section{Conclusão}

O Gerenciamento da rotina e as ferramentas da qualidade podem ser utilizados em diversos tipos de segmentos, desde empresas que produzem, à empresas de serviços. A implantação demonstra que, com o comprometimento da gestão corporativa da empresa e o trabalho, do operacional ao estratégico, torna-se sob controle, padronizado e, quaisquer variações que possam ocorrer, serão analisadas de forma estruturada, para entender suas causas e eliminá-las.

As ferramentas e metodologias adotadas se mostraram eficazes em relação à redução de perda de produtos por questões de validade, além de conseguirem benefícios secundários, como a entrega dos produtos em tempo hábil atrelado a uma logística bem trabalhada.
Foi alcançada a redução em $90 \%$ dos produtos vencidos, maior disponibilidade dos setores com ações do 5S, gerenciando uma rotina dia a dia, ambientes com melhor circulação e limpeza. Todas as mudanças contribuíram para que a empresa optasse por manter o GRD, as ferramentas e metodologias adotadas, ou seja, uma nova forma de gestão, para acompanhar o mercado que hoje em dia está cada vez mais exigente.

Os resultados apresentados, as melhorias, 0 atendimento ao cliente e um ambiente de trabalho harmonioso permitiram que a empresa aumentasse sua excelência no serviço, tornando-a cada vez mais competitiva no mercado alcançando altos indicies de satisfação.

\section{Referências}

[1] LOPES, H. E. G., PEREIRA, C. C. DE P. AND VI-EIRA, A. F. S.. Comparação entre os modelos norte-americano (ACSI) e europeu (ECSI) de vertisfação do cliente: um estudo no setor de serviços. RAM, Ver. Adm. Mackenzie (Online), Fev. 2009, vol.10, no.1, p.161-187. ISSN 16786971.

[2] MELLO, C.H.; PEREIRA de ET AL: ISO 9001:2000 - Sistema de gestão da qualidade para operações de produção e serviços. São Paulo: Atlas, 2006.

[3] GOMES, Ricardo Caio Ávila; CERVI, Roberto. A utilização de ferramentas da qualidade para identificação das causas do desperdício em uma empresa do ramo da construção civil recémconstituída. UFPR, 2013.

[4] MEIRELES, Manuel. Ferramentas Administrativas para identificar, observar e analisar problemas. Arte \& Ciência, 2001.

[5] ROZENFELD, H.; AMARAL, D.C; FORCELLINI, F.A.; TOLEDO; J.C.; SILVA, S.L.; ALLIPRANDINI, D.H.; SCALICE, R.K., Gestão do Desenvolvimento de Produtos: Uma referência para a melhoria do processo. Saraiva, São Paulo, 2006.

[6] GOUVÊA, E. M. Disponível em:<http://improveeng.blogspot.com.br/2011/03 /check-list-como-ferramenta-de-qualidade.html. > Acesso em Agosto de 2017. 
[7] SEBRAE. Manual de Ferramentas da Qualidade,

2005.Disponívelm:<http://www.dequi.eel.usp.br/ $\sim$ barcza/ferramentasdaqualidadeSEBRAE.pdf>

Acesso em Fevereiro de 2017.

[8] MOURA, L. R. Qualidade Simplesmente Total: uma abordagem simples e prática da gestão da Qualidade, Rio de Janeiro: Qualitymarl, 1997.

[9] CAMPOS, V. F. Gerenciamento da rotina do trabalho do dia-a-dia. Belo Horizonte: Editora de Desenvolvimento Gerencial, 1998.

[10] SANTOS, E. G.; LIMA, I. F.; ABRANTES, M. P. S., Gerenciamento da rotina diária em unidades de informação. Disponível em: http://dici.ibict.br/archive/00000714/01/T054.

Acesso em Fevereiro 2018.

[11] C. Portal. Programa 5S S: objetivos gerais.

https://www.portaleducacao.com.br/administraca o/artigos/55171/programa-5s-s-objetivos-gerais. Acesso em Novembro de 2016.

[12] W. M. Andrade. O que é 5S. Disponível em:< http://5s.com.br/2/o-que-e-5s.php.> Acesso em Março de 2017. 